\title{
Are Gritty People Happier than Others?: Evidence from the United States and South Korea
}

\author{
Hye Won Kwon ${ }^{1}$ (D)
}

Accepted: 4 December 2020 / Published online: 12 January 2021

(C) The Author(s) 2021

\begin{abstract}
Grit, which refers to perseverance and passion to pursue long-term goals, has been highlighted as a predictor of better life outcomes, including subjective well-being. For grit to be useful for well-being research, we need to know more about its properties across cultures and determine whether it has a relationship to well-being outcomes beyond other existing psychological measures. Using survey data from the United States and South Korea $(\mathrm{N}=1008)$, this study examines the measurement of grit across cultures as having two dimensions: perseverance of effort and consistency of interest. It then explores the distinctive utility of grit in explaining an individual's subjective well-being beyond wellestablished psychological measures such as conscientiousness and sense of control. The results show that gritty people report better subjective well-being; this positive relationship between grit and subjective well-being is largely driven by the perseverance dimension of grit. This dimension accounts for a unique variance in subjective well-being beyond the sense of control in both country samples and variance beyond conscientiousness in the US sample. By contrast, the consistency dimension of grit adds little to our understanding of subjective well-being in either country. Relying on the global grit score, which aggregates the scores of the two dimensions, may obscure the unique role of the perseverance dimension in understanding subjective well-being.
\end{abstract}

Keywords Grit · Subjective well-being · Conscientiousness $\cdot$ Sense of control

\section{Introduction}

Grit, the ability to stay focused and dedicate persistent effort towards a long-term goal, has received extensive attention from parents and educators, since it is known to be a highly predictive indicator of achievement (e.g., Duckworth et al. 2007; Duckworth and Quinn 2009; Eskreis-Winkler et al. 2014). While previous studies on grit emphasized its role in predicting objective indicators of success, such as educational and professional outcomes, some turned their attention to another consequence of having

Hye Won Kwon

hye.kwon@utu.fi

1 INVEST Research Flagship Sociology, University of Turku, Assistentinkatu 7, 20500 Turku, Finland 
grit-subjective well-being. People with high grit tend to report higher levels of happiness and life satisfaction and better mental health (e.g., Salles et al. 2014; Vainio and Daukantaitè 2016).

Theoretically, grit is a higher-order construct that is composed of two dimensionsperseverance of effort and consistency of interest (Duckworth et al. 2007). However, Credé et al. (2017) documented that previous empirical studies reported mixed findings: some studies reported that the two first-order factors are often uncorrelated or are only weakly correlated while other studies reported strong correlations between the two. Several studies suggested using the two-factor structure of grit, in lieu of the hierarchical model of grit, demonstrating its greater validity as compared to the hierarchical model (e.g., Datu et al. 2016). In line with this debate over the psychometric properties of the grit scale, some studies used the scores of the two dimensions separately and showed different roles of each dimension in outcome variables, including academic achievement and well-being (e.g., Bowman et al. 2015; Datu et al. 2016; Hwang et al. 2018). The majority of prior studies have relied heavily on selective samples (e.g., college students) in a single country, particularly in the United States, and thus, little is known about whether the grit scale operates similarly across different cultures (for a rare exception, see Disabato et al. 2019). Further examination of the measurement of grit should be conducted using more representative samples across different countries.

Another debate is still ongoing about whether grit can be distinguished from other existing psychological measures with well-documented links to improved life outcomes. Among them, this study focuses on two psychological constructs that relate to both grit and subjective well-being: conscientiousness and sense of control. The high correlation between grit and conscientiousness casts doubts on the distinct utility of grit, mostly in predicting academic performance (e.g., Credé et al. 2017; Ivcevic and Brackett 2014). Little is known about grit's utility, distinct from conscientiousness, to account for a unique variance in another important outcome, subjective well-being. Subjective wellbeing has been effectively linked to a sense of control (see Ross and Mirowsky 2013 for a review), but this has not been studied in conjunction with grit. Duckworth et al. (2007) suggested that having a stronger mastery belief could motivate people to develop a grittier inclination: people who believe they can control their life outcomes (i.e., a higher sense of control) likely have passion and work hard to achieve their goals (i.e., a higher level of grit). Despite this potential connection among the sense of control, grit, and subjective well-being, no study has investigated how grit accounts for variances in subjective well-being above and beyond the sense of control. Given that conscientiousness and sense of control are closely related to both grit and subjective well-being, it is important to explore any unique contribution of grit in accounting for subjective wellbeing over these well-established measures.

This study addresses three research questions, using survey data collected in the United States and South Korea: (1) What is the factor model of the Short Grit Scale (Grit-S) in the current cross-cultural samples? (2) Can the grit measure be applied to the South Korean context? (3) Is grit positively associated with subjective well-being, net of the sense of control and conscientiousness that closely relate to both grit and subjective well-being? This paper assesses the psychometric properties of the Grit-S scale in the United States, where the grit scale was developed and has been studied predominantly, and in South Korea, a collectivistic country in which the concept and measurement of grit have not yet been firmly established. A multi-group confirmatory factor analysis was conducted to assess the measurement invariance of the Grit-S scale across the two country samples. In addition, 
the distinctive utility of grit in explaining the variance in subjective well-being, beyond conscientiousness and sense of control, is examined in each country.

\section{Literature Review}

\subsection{Grit: Persistent Effort and Consistent Interest}

Grit refers to the ability to persistently try and maintain consistent interest in pursuit of a long-term goal (Duckworth et al. 2007). Gritty people are characterized as rarely giving up on a goal, working hard and not easily shifting their interest from one goal to another despite obstacles. Those who lack grit tend to change their goals more easily and not persevere (Duckworth et al. 2011; Duckworth and Quinn 2009; Robertson-Kraft and Duckworth 2014).

Grit researchers operationalize grit as a concept consisting of two dimensions: perseverance of effort and consistency of interest (e.g., Duckworth et al. 2007). They propose a second-order model of grit scale, modeling grit as a second-order latent concept measured by the two first-order dimensions (i.e., perseverance of effort and consistency of interest). Duckworth and her colleagues supported this hierarchical model of the original Grit scale (Grit-O) with 12 items (Duckworth et al. 2007) and the abovementioned Grit-S scale with eight items (Duckworth and Quinn 2009). Following this practice, the majority of prior research has used the global grit measure, which aggregates the scores of two dimensions (e.g., Blalock et al. 2015; Ivcevic and Brackett 2014; Salles et al. 2014). This practice should be used with caution, however. A recent meta-analysis by Credé et al. (2017) shows that the higher-order structure of grit is not supported. In line with that, researchers often use two dimension scores separately instead of the overall grit score, and show distinctive roles of two dimensions accounting for outcome variables (e.g., Bowman et al. 2015; Hwang et al. 2018). Even among these studies, only a few studies have empirically demonstrated the validity of the two-factor structure of the grit scales to support their reports of separate results of each dimension. These measurement studies, however, relied on relatively selective, non-representative samples-for example, Filipino students at a university and a high school (Datu et al. 2016), an online sample recruited by Amazon's Mechanical Turk (MTurk) (Abuhassàn and Bates 2015), and an international online sample recruited by snowball sampling (Disabato et al. 2019). Although these studies improved our understanding of grit across cultures, more empirical examinations of grit using more general samples across different countries are necessary.

\subsection{Grit and Subjective Well-Being}

Grit has increasingly gained the attention of parents and educators, as prior studies have documented that a person's grit is highly predictive of achievement in many challenging fields, ranging from Ivy League undergraduate student academic outcomes to retention in the US Military Academy at West Point (Duckworth et al. 2007, 2011; Duckworth and Quinn 2009; Eskreis-Winkler et al. 2014). While public attention has focused heavily on grit's association with achievement, grit has been also highlighted as a predictor of mental well-being across countries. Grit is positively related to general subjective well-being among undergraduate students at an Indian university (Singh and Jha 2008) and residents 
in general surgery in the United States (Salles et al. 2014). Gritty students in the Philippines tend to report less depression (Datu et al. 2019), as do Latinx first-generation college students in the United States (O'Neal et al. 2016). Grit, along with gratitude, is also negatively associated with suicidal ideation by enhancing meaning in life (Kleiman et al. 2013), and serves as a buffer against the effect of negative life events on suicidal ideation among undergraduates in the United States (Blalock et al. 2015).

Why are gritty people generally happier and more satisfied with life than others? One explanation could be drawn from the invest-and-accrue model, which was proposed by Hill and Jackson (2016) to theorize the relationship between conscientiousness and positive life outcomes (Disabato et al. 2019). Gritty people tend to invest more in the behavior needed to achieve their goals, which could result in better outcomes, including greater academic and professional achievement (Duckworth et al. 2011; Eskeis-Winkler et al. 2014; Hwang et al. 2018). They also invest more in healthier behaviors than other people do (Reed et al. 2013; Sharkey et al. 2017). Better objective life outcomes and better health, in turn, could lead them to feel more satisfied with life.

This link between grit and subjective well-being could be largely due to the strong positive association between the perseverance of effort and subjective well-being (Disabato et al. 2019). Even though most studies rely on global grit, the two dimensions of grit appear to play different roles in shaping subjective well-being. Disabato et al. (2019) found that the perseverance of effort is positively associated with subjective well-being, while the consistency of interest is unrelated or even negatively associated with subjective well-being across countries. Datu et al. (2016) also found that perseverance is positively associated with the subjective well-being of Filipino college and high school students.

By contrast, sticking to one goal for months or years (i.e., consistency of interest) may not be such a helpful skill in achieving better outcomes. For example, Credé et al. (2017) reported that perseverance has a strong predictive power in explaining academic outcomes, while less evidence is found to support consistency of interest as a predictor of academic achievement. Furthermore, sticking to the same goal over the years despite setbacks may not necessarily be helpful for one's mental well-being. When achieving a certain goal seems unrealistic and a person experiences failures repeatedly, it may be better for the person's mental well-being to change the goal rather than adhere to the same goal. Thus, I hypothesize that while grit is positively associated with subjective well-being, the positive relationship is more pronounced in the perseverance facet of grit.

\subsection{Correlates of Grit: Sense of Control and Conscientiousness}

This study examines two theoretically driven psychological correlates of grit, one more common in sociology, the other a core dimension of personality: a sense of control and conscientiousness. A sense of control-the belief that a person is responsible for his/her life outcomes (Mirowsky and Ross 1991) - has been reported to be an important psychological resource that is beneficial for one's well-being (see Ross and Mirowsky 2013 for a review). People with a higher sense of control do not attribute their life outcomes to external factors such as fate or luck; rather, they believe they have agency and power to achieve the life outcomes they want. Having this subjective belief about one's control contributes to better achievement, health, and subjective well-being (e.g., Lachman and Weaver 1998; Mirowsky and Ross 1998; You, Hong, and Ho 2011). Those who have a higher sense of control tend to report lower levels of psychological distress and enjoy better subjective well-being than others (Ross and Mirowsky 2013 for a review). 
A potential relationship between grit and a sense of control has been suggested (Duckworth et al. 2007). A person who believes in being fully responsible for their life outcomes (i.e., a stronger sense of control) likely shows sustained efforts and interests in life projects (i.e., a higher level of grit). Grit and the sense of control are closely related but distinct concepts. While the sense of control captures subjective beliefs about one's agency, grit taps into more behavioral inclinations that potentially transfer one's beliefs to actual behaviors that lead to certain outcomes (Kwon 2017). These two crucial psychological resources, however, have not been empirically examined together. Given that sense of control has been heavily studied in sociology as a strong predictor of subjective well-being (see Ross and Mirowsky 2013 for a review), examining the incremental validity of grit over sense of control, which is a traditional and conventional psychological measure that has a well-established link to subjective well-being, is important to demonstrate the possible utility of grit.

Another existing psychological measure that relates to grit and subjective well-being is conscientiousness. The positive link between conscientiousness and subjective well-being has been documented in the literature: conscientious people tend to be more satisfied with life and report more positive affect and less negative affect (e.g., Steel, Schmidt, and Shultz 2008), less mental illness (e.g., Kotov et al. 2010), more health-promoting behaviors, better physical health, and longevity (e.g., Deary et al. 2010; Roberts, Walton, and Bogg 2005).

Conscientiousness, a personality trait of being orderly, dependable, and responsible (John and Srivastava 1999), is one dimension of the "Big Five" personality traits that has been reported as being very closely related to grit (Credé et al. 2017; Duckworth and Quinn 2009). Grit researchers have endeavored to distinguish the concept of grit from conscientiousness, arguing that grit highlights one's tendency to work on long-term projects rather than immediate tasks (Duckworth et al. 2007; Duckworth and Eskreis-Winkler 2013). While some researchers found evidence for grit's incremental validity in predicting better achievement (Duckworth et al. 2007; Eskreis-Winkler et al. 2014) and exercise behaviors (Reed et al. 2013) beyond conscientiousness, others did not find such a distinct, significant effect of grit on academic achievement (e.g., Ivcevic and Brackett 2014; Rimfeld et al. 2016) and work performance (Ion, Mindu, and Gorbănescu 2017), controlling for conscientiousness. Consistent with this, Credé et al. (2017) questioned the distinctive utility of grit beyond conscientiousness: their meta-analysis found a very strong correlation between grit and conscientiousness in the previous studies. Also, Schmidt et al. (2018) found the overall grit scale and grit's two dimensions highly correlate with different facets of conscientiousness. This set of mixed results calls for more empirical exploration of the grit's relation to outcome variables beyond conscientiousness.

Sense of control involves the learned and generalized expectation that one controls one's own life while grit (and likely also conscientiousness) taps more into behavioral inclinations and practices whereby an individual transforms such beliefs into their actual practices in daily life. Therefore, theoretically, the sense of control is a psychological construct that is related (see Table 2 for the correlation scores) but distinct from both grit and conscientiousness. Prior research has not examined grit's relationship with subjective wellbeing, beyond conscientiousness and the sense of control. To clarify whether and why grit matters to well-being research, the present study explores whether grit explains a unique variance in subjective well-being beyond these psychological correlates of grit (i.e., conscientiousness and the sense of control) with a more representative set of societal samples. 


\subsection{Grit in Different Societies}

While several prior studies have documented the positive association between grit and well-being, most rely on relatively selective populations, such as college students (Blalock et al. 2015; Kleiman et al. 2013; O'Neal et al. 2016) or general surgery residents (Salles et al. 2014) who are residing in a single country, mostly in the United States. Datu et al. (2016) pointed out that prior grit research has heavily focused on Western countries, and the examination of grit measures in non-Western contexts is limited. Little is known about how the grit measures operate in shaping one's subjective well-being beyond its correlates in a collectivistic setting.

Only a few studies have investigated the relationship between grit and subjective well-being in non-Western societies, including the Philippines, Hong Kong, and India (e.g., Datu et al. 2016, 2019; Lee 2017; Singh and Jha 2008), but also with relatively selective samples (i.e., high school and college students). As a rare exception, Disabato et al. (2019) examined the relationship between grit and subjective well-being across different cultural regions using survey data collected from 109 countries through snowball sampling methods. Using the separate dimension scores of the Grit-O scale based on their measurement test, they found that perseverance of effort is positively associated with subjective well-being, while consistency of interest is not related, or even negatively related to well-being. This finding is consistent with what Datu et al. (2016) found using data from Filipino college and high school students: the perseverance dimension of grit is a stronger predictor of subjective well-being. By contrast, Lee (2017) found significant negative associations between both dimensions of grit and stress among community college students in Hong Kong. This set of mixed findings using different samples calls for further assessment of the grit scale and its validity in understanding subjective well-being in different countries, using more general samples. Besides, none of these studies examine close correlates of grit (i.e., conscientiousness) when demonstrating grit's role in understanding subjective well-being in different cultures, calling for future research on grit's role in subjective well-being, controlling for conscientiousness (Disabato et al. 2019).

To address this gap, the present study focuses on two countries, the United States and South Korea, to examine grit. Despite the presumed cultural differences between these two countries (e.g., based on the widely cited cultural dimension of individualism vs. collectivism, see Hofstede 1980), the concept of grit could be applied to the Korean context. For instance, Confucian traditions, which have long been served as dominant cultural ideologies in Korean society, emphasize diligence and hard work as desirable virtues (Kim and Park 2003). This implicitly suggests that grit can be also highly valued as an essential psychological functioning in South Korea. However, little is known if the measurement structure is identical in these two cultural contexts, or if they operate similarly with respect to subjective well-being.

This study examines the structure of the Grit-S scale and its applicability to the current samples and investigates the distinctive utility of grit in explaining subjective well-being beyond conscientiousness and sense of control. The latter part of the analysis presents two sets of results, using global grit and using two dimensions of grit separately. This approach helps examine whether the variance in well-being explained by the overall grit score is driven predominantly by one dimension (e.g., perseverance) more than the other (e.g., consistency). Drawing on recent cross-cultural findings (Datu et al. 2016; Disabato et al. 2019), I hypothesize that global grit is positively associated with subjective well-being, and 
Table 1 Demographic statistics

\begin{tabular}{|c|c|c|c|c|c|c|c|c|}
\hline \multirow[t]{2}{*}{ Variable } & \multicolumn{4}{|c|}{ USA $(\mathrm{N}=533)$} & \multicolumn{4}{|c|}{ South Korea $(\mathrm{N}=475)$} \\
\hline & Mean & SD & Min & $\operatorname{Max}$ & Mean & SD & Min & $\operatorname{Max}$ \\
\hline Age & 46.65 & 16.15 & 18 & 85 & 42.31 & 13.70 & 18 & 82 \\
\hline Female & 0.50 & 0.50 & 0 & 1 & 0.50 & 0.50 & 0 & 1 \\
\hline White & 0.83 & 0.37 & 0 & 1 & & & & \\
\hline College & 0.44 & 0.50 & 0 & 1 & 0.59 & 0.49 & 0 & 1 \\
\hline Household income & 5.90 & 3.16 & 1 & 11 & 5.89 & 2.95 & 1 & 11 \\
\hline Religiosity & 5.30 & 3.54 & 0 & 10 & 3.65 & 3.09 & 0 & 10 \\
\hline Married & 0.48 & 0.50 & 0 & 1 & 0.53 & 0.50 & 0 & 1 \\
\hline Happiness & 7.20 & 2.07 & 0 & 10 & 5.95 & 2.03 & 0 & 10 \\
\hline Life satisfaction & 6.85 & 2.34 & 0 & 10 & 5.65 & 2.05 & 0 & 10 \\
\hline
\end{tabular}

having more perseverance of effort shows a stronger positive association with subjective well-being than having a higher consistency of interest. In addition, the benefit of having a higher level of perseverance is important for explaining the variance in subjective wellbeing beyond the sense of control in both country samples, providing cross-cultural evidence for its distinctive utility in predicting subjective well-being beyond the sense of control. By contrast, given high correlation scores between grit and conscientiousness reported by prior studies (see Credé et al. 2017 for meta-analysis results), I hypothesize that the distinctive utility of grit measures beyond conscientiousness is less pronounced.

\section{Methods}

\subsection{Data}

To expand our understanding of grit beyond the United States, where the majority of grit research has been conducted, the current study relies on original cross-cultural survey data collected from two countries: the United States and South Korea. This data collection received approval from the Institutional Review Board of the study's home institution, the University of Iowa. For this study, Qualtrics panels recruited respondents from national panels of American and South Korean participants. Quota sampling on age groups, gender, and household income in each country was used to recruit samples that attempt to represent these demographic characteristics of a population. Using Qualtrics panels is not unusual in social science research (e.g., Djupe, Neiheisel, and Sokhey 2018; Johnson et al. 2015). Although Qualtrics panels provide nonprobability samples, prior studies have documented that they often outperform other online samples including MTurk and produce results relatively close to those of nationally representative probability samples (Boas et al. 2018; Zack et al. 2019). Nonetheless, researchers must draw conclusions from online nonprobability samples with caution. Accordingly, the present study does not intend to generalize the results beyond the current samples. Initial sample sizes were 546 for the US data and 475 for the Korean data. The analysis was limited to the respondents who completed 
survey items of interest (533 for the US data and 475 for the Korean data). ${ }^{1}$ The demographic characteristics of each sample are summarized in Table $1 .{ }^{2}$

\subsection{Measures}

The survey instrument contains the Grit-S Scale; the Personal Sense of Control Scale; a conscientiousness measure from the "Big Five" personality traits; subjective well-being measures, including life satisfaction and happiness; and a set of demographic questions. The Korean versions of the sense of control, grit, and conscientiousness questions that are not available in the existing international surveys were translated using the translation-back translation method (Brislin 1970). Table 2 presents descriptive statistics for key measures.

Grit was measured by the Grit-S scale (Duckworth and Quinn 2009). Seeing grit as a higher-order construct consisting of two lower-order dimensions-the perseverance of effort (hereafter, perseverance) and consistency of interest (hereafter, consistency), four statements such as "I finish whatever I begin" and "Setbacks don't discourage me" were used to measure the perseverance dimension of grit, while four statements such as "I often set a goal but later choose to pursue a different one" and "I have difficulty maintaining my focus on projects that take more than a few months to complete" were used to measure the consistency dimension. Responses ranged from 1 "Very much like me" to 5 "Not like me at all." Responses to the perseverance statements were reverse coded so that a higher score indicates a higher level of grit. Cronbach's reliability coefficients were high in both country samples ( 0.74 for the US sample; 0.75 for the Korean sample). In addition to the Grit-S composite, the scores for two dimensions, perseverance and consistency, were computed by averaging responses under each dimension $\left(\alpha_{\text {perseverance }}=0.78\right.$ and $\alpha_{\text {consistency }}=0.85$ for the US sample; $\alpha_{\text {perseverance }}=0.77$ and $\alpha_{\text {consistency }}=0.71$ for the Korean sample).

The sense of control was measured by the Personal Sense of Control scale (Mirowsky and Ross 1991), which includes questions such as "I can do just about anything I really set my mind to" (claiming control) and "There's no sense of planning a lot-if something good is going to happen, it will" (denying control). Responses ranged from - 2 "Strongly disagree" to 2 "Strongly agree" on a five-point scale. Responses to the statements of denying control were reverse coded so that a higher score indicates a higher level of personal control. Cronbach's reliability coefficients were high in the US sample $(\alpha=0.70)$ and relatively lower than conventional criteria in the Korean sample $(\alpha=0.57)$.

Conscientiousness was measured by the scale (i.e., the Big Five Inventory) suggested by John and Srivastava (1999). Respondents were asked to report how strongly they agree or disagree with statements that describe themselves such as "does a thorough job" and "is a reliable worker." Responses ranged from 1 "Strongly disagree" to 5 "Strongly agree." Statements that describe a lack of conscientiousness (i.e., "is easily distracted") were reverse coded so that a higher score means a higher level of conscientiousness. Cronbach's reliability coefficients were high in both the US $(\alpha=0.86)$ and Korean samples $(\alpha=0.85)$.

Subjective well-being was measured by averaging two variables (Delhey and Dragolov 2014), happiness and life satisfaction ( $\alpha=0.87$ in the US; $\alpha=0.91$ in South Korea). Over

\footnotetext{
${ }^{1}$ All missing cases $(n=13)$ were found in the US sample: one case on happiness, one case on grit, eight cases on sense of control and conscientiousness, and three cases on race/ethnicity (white), education (college), and marital status (married).

2 Korean respondents younger than 55 years of age were slightly oversampled because of a shortage of participants who are 55 years old or older in the Korean panel.
} 


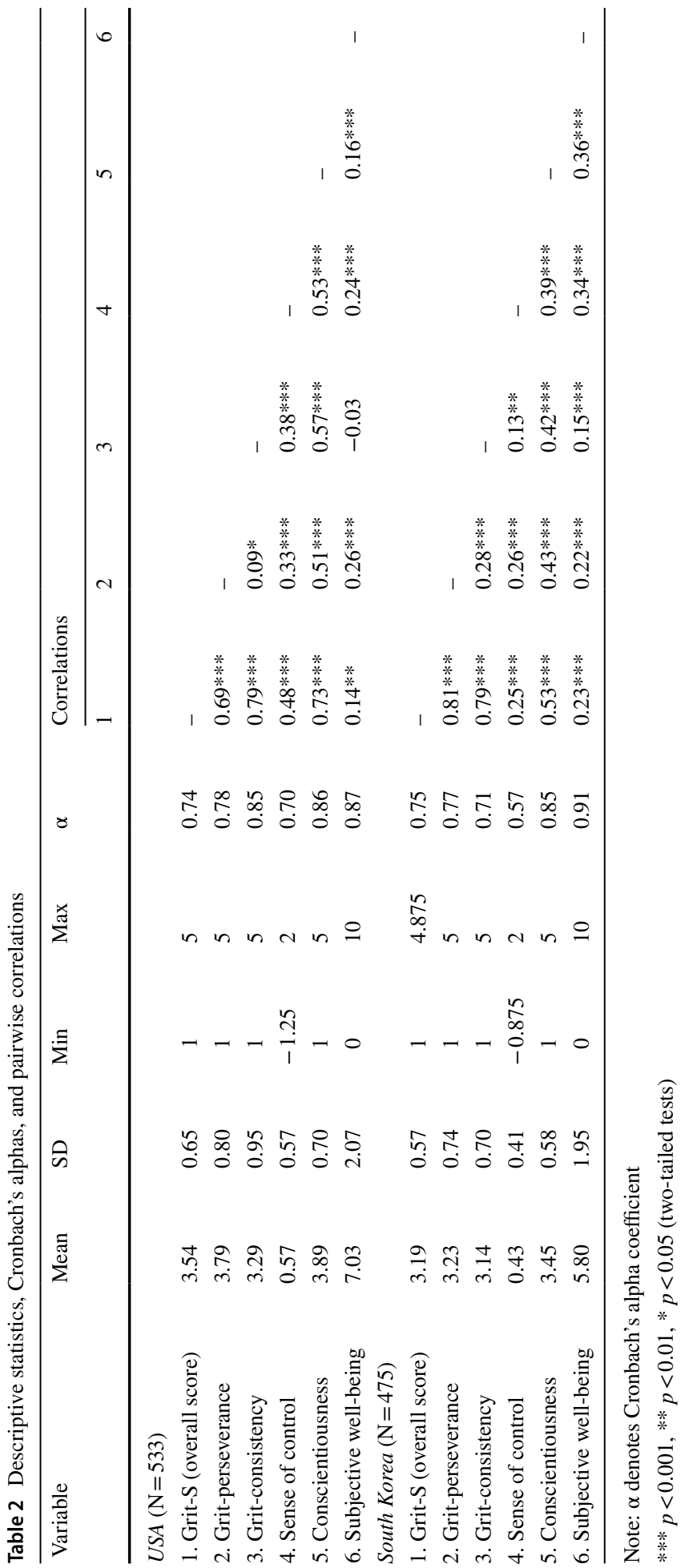


the past several decades, research on subjective well-being has relied on multiple measures of subjective well-being across disciplines (see Linton et al. 2016 for a systematic review on the lack of consensus on the well-being measures). The most widely cited is Diener's model, which views subjective well-being as a multifaceted construct that is comprised of four components: life satisfaction, positive affect, negative affect, and domain satisfaction (Diener et al. 1999). The current subjective well-being measure captures part of the multifaceted subjective well-being (Diener et al. 2009; see Diener 2006 for discussion about using life satisfaction and happiness as global subjective well-being measures), although it is not perfect. ${ }^{3}$ The present study uses survey items available in the existing international surveys, such as the European Social Survey, World Values Survey, and International Social Survey Program, to capture a person's global assessment of happiness and life satisfaction (Diener et al. 2000). For happiness, respondents were asked to answer this question: "Taking all things together, how happy would you say you are?" on an 11-point scale ranging from 0 "Extremely unhappy" to 10 "Extremely happy."4 Life satisfaction was measured with the following question: "All things considered, how satisfied are you with your life as a whole nowadays?" with responses ranging from 0 "Extremely dissatisfied" to 10 "Extremely satisfied."

I controlled for several demographic variables that have been shown in previous research to correlate with an individual's subjective well-being (see Diener et al. 1999 for a review) including age, gender $(1=$ female, $0=$ male), race/ethnicity (only in the US model; $1=$ white, $0=$ others), marital status $(1=$ married, $0=$ not married), and religiosity (ranged from 0 "not religious at all" to 10 "very religious"). College $(1=$ college degree, $0=$ without a college degree) and household income (11 categories based on deciles of the actual household income range of each country, with the last category reflecting the top 5\%) are also included in the analysis. One important point I should note here is that there is potential bias as I include these two variables: grit could contribute to better educational attainment and household income, and college and household income could mediate the effect of grit on subjective well-being, resulting in an underestimation of the effect of grit on subjective well-being (i.e., overcontrol bias; Rohrer 2018). However, there is another possibility that these variables could operate as confounders of the relationship between grit and subjective well-being because one's socioeconomic status (e.g., structural conditions) could provide individuals with the opportunity to develop psychological resources including grit, and this, in turn, benefits their subjective well-being. Omitting them in the analysis could result in a confounding bias. Since both possibilities cannot be ruled out in this study due to its cross-sectional design, I present the models with both variables included as the main analysis but also present, in the "Appendix", a separate set of results without these variables to aid better assessment of the results..$^{5}$

\footnotetext{
${ }^{3}$ A more refined measure could include all four components with more specific indicators of each component to better assess a person's subjective well-being.

${ }^{4}$ The current measure of happiness likely captures global happiness, a summary index of positive affect that a person experiences in general. While prior studies often used this happiness item to measure positive affect as part of subjective well-being (e.g., Goodman et al. 2018), a more precise measure could include indicators of diverse positive emotions (e.g., Diener et al. 1999; see Lyubomirsky and Lepper 1999 for discussion of happiness measures).

${ }^{5}$ The estimates of grit measures were slightly higher when college and household income were excluded, but there was no significant difference in the results.
} 
Table 3 Fit indices of the hypothesized models of grit

\begin{tabular}{lrllllll}
\hline Model & S-B $\chi^{2}$ & $d f$ & $p$ & CFI & TLI & RMSEA & SRMR \\
\hline USA (N=533) & & & & & & & \\
1. Unidimensional model & 704.168 & 20 & 0.000 & 0.538 & 0.353 & 0.253 & 0.190 \\
2. Two-factor model & 63.589 & 19 & 0.000 & 0.970 & 0.956 & 0.066 & 0.061 \\
3. Two-factor model with modification & 40.880 & 18 & 0.002 & 0.985 & 0.976 & 0.049 & 0.050 \\
South Korea (N=475) & & & & & & & \\
1. Unidimensional model & 297.496 & 20 & 0.000 & 0.698 & 0.577 & 0.171 & 0.123 \\
2. Two-factor model & 78.187 & 19 & 0.000 & 0.936 & 0.905 & 0.081 & 0.064 \\
3. Two-factor model with modification & 57.986 & 18 & 0.000 & 0.956 & 0.932 & 0.068 & 0.053 \\
\hline
\end{tabular}

\section{Results}

\subsection{Measurement Tests of the Grit-S scale}

\subsubsection{The Factor Structure of Grit-S}

Building on prior studies that validated the Grit scale in different samples, including online (Abuhassàn and Bates 2015) and non-Western samples (Datu et al. 2016), I tested three hypothesized models in this study: (a) a hierarchical model of grit, (b) a unidimensional structure of grit, and (c) a two-factor model of grit. The maximum likelihood meanadjusted (MLM) estimation in Mplus 8.3 was used to handle the multivariate non-normality of the data distribution. Model fit was assessed using the Chi-square statistic $\left(\chi^{2}\right)$, the root mean square error of approximation (RMSEA), the comparative fit index (CFI), the Tucker-Lewis index (TLI), and standardized root mean residual (SRMR). An insignificant Chi-square statistic $(p>0.05)$, values of 0.95 or above for the CFI and TLI, values of 0.06 or less for the RMSEA, and values of 0.08 or less for the SRMR were considered to indicate a good fit (Hu and Bentler 1999). Values close to 0.90 for the CFI and TLI and values close to 0.08 for the RMSEA were considered to indicate an acceptable fit (Bentler 1990).

A higher-order model that conceptualizes a hierarchical structure of grit in which two first-order factors are under a higher-order latent variable (grit) did not converge in both samples because a higher-order model with unique factor loadings of the two first-order factors cannot be psychometrically identified (see Credé et al. 2017 for further discussion). ${ }^{6}$ A unidimensional model of grit that conceptualizes all grit items under one latent variable (grit) produced a poor fit in both countries (see Table 3).

I tested the two-factor structure of the grit scale, in which two latent constructs (perseverance and consistency; four items each) are allowed to be correlated. The twofactor model produced good fit indices for the US sample $\left(\mathrm{S}-\mathrm{B} \chi^{2}=63.589, d f=19\right.$, $\mathrm{CFI}=0.970, \mathrm{TLI}=0.956, \mathrm{RMSEA}=0.066, \mathrm{SRMR}=0.061)$ and acceptable fit indices for the Korean sample $\left(\mathrm{S}-\mathrm{B} \chi^{2}=78.187, d f=19, \mathrm{CFI}=0.936, \mathrm{TLI}=0.905, \mathrm{RMSEA}=0.081\right.$, SRMR $=0.064)$. A better-fitted model was yielded with a cross-loading of consistency item four, "I have difficulty maintaining my focus on projects that take more than a few

\footnotetext{
${ }^{6}$ We can make the higher-order model identified by constraining the factor loadings of the two first-order factors to one, but it is equivalent to the two-factor model.
} 


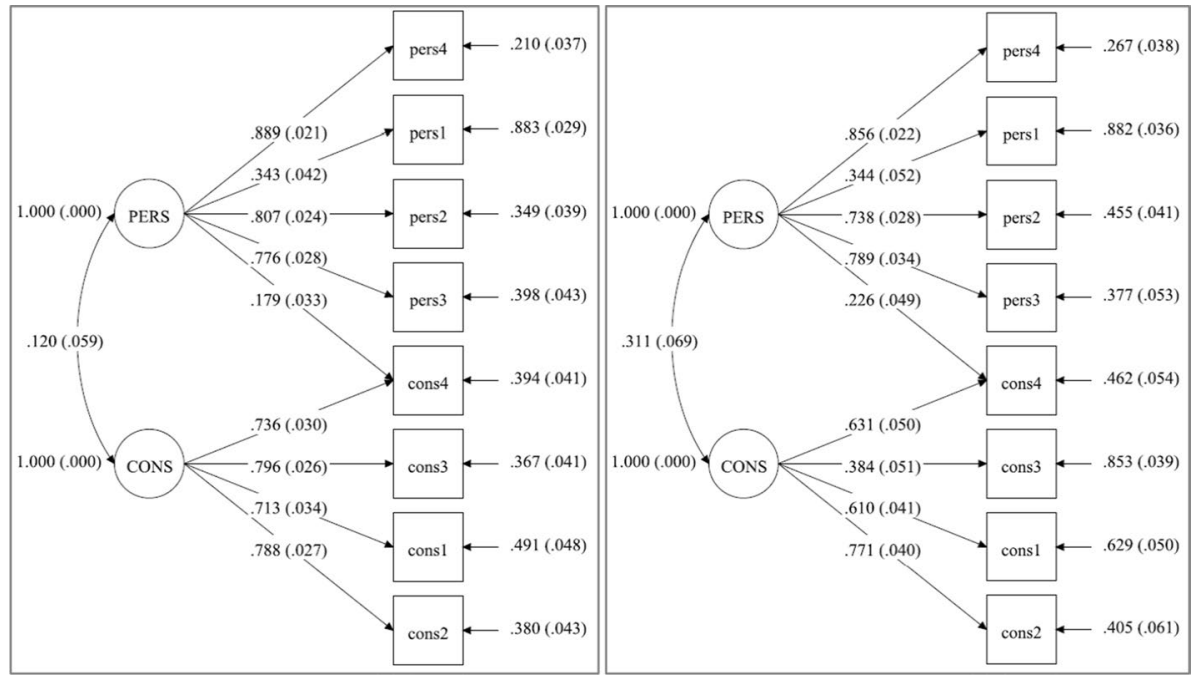

Fig. 1 Test results of the two-factor model with modification. Note: The US result on the left and the Korean result on the right. PERS refers to the perseverance of effort and CONS refers to the consistency of interest. Standardized coefficients are presented with standard errors in parenthesis. All the paths presented are significant at $p<0.05$

Table 4 Goodness-of-fit indices in the MGCFA

\begin{tabular}{lrlllllllll}
\hline & $\mathrm{S}-\mathrm{B} \chi^{2}$ & $d f$ & $p$ & CFI & TLI & RMSEA & $\Delta$ CFI & $\Delta$ S-B $\chi^{2}$ & $\Delta d f$ & sig \\
\hline Configural invariance & 98.634 & 36 & 0.000 & 0.974 & 0.959 & 0.059 & & & & \\
Metric invariance & 144.895 & 43 & 0.000 & 0.957 & 0.945 & 0.069 & -0.017 & 50.762 & 7 & $<0.05$ \\
Partial metric invariance & 108.513 & 42 & 0.000 & 0.972 & 0.963 & 0.056 & -0.002 & 9.029 & 6 & $>0.05$ \\
\hline
\end{tabular}

months to complete" $\left(\mathrm{S}-\mathrm{B} \chi^{2}=40.880, d f=18, \mathrm{CFI}=0.985, \mathrm{TLI}=0.976, \mathrm{RMSEA}=0.049\right.$, $\mathrm{SRMR}=0.050$ in the US sample and $\mathrm{S}-\mathrm{B} \chi^{2}=57.986, d f=18, \mathrm{CFI}=0.956, \mathrm{TLI}=0.932$, RMSEA $=0.068$, SRMR $=0.053$ in the Korean sample). ${ }^{7}$ All items were significantly loaded on the designated grit factors, and the two latent variables were correlated with each other in both samples (see Fig. 1). Taken together, the results support the two-factor model with a cross-loading in both samples.

\footnotetext{
${ }^{7}$ Modification indices in both country samples commonly suggested a cross-loading of this item onto the perseverance dimension. This item likely taps into persistence in goal pursuit, which overlaps with perseverance, as it is the only consistency item that highlights a long-term dedication to projects (e.g., "projects that take more than a few months to complete"). Pairwise correlation results show that this item positively correlates with perseverance items, with correlation scores ranging from 0.17 to 0.37 in the Korean sample and from 0.21 to 0.24 in the US sample $(p<0.05)$. One exception was perseverance item one (i.e., "Setbacks don't discourage me"), which was not significantly correlated with consistency item four in the US sample $(r=-0.03, p>0.05)$.
} 


\subsubsection{Measurement Invariance Test}

Using the two-factor model with a cross-loading of consistency item four, which shows a better fit for both countries' data, I conducted an MGCFA analysis and tested the measurement invariance of the Grit-S scale across the two country samples (Table 4). Model fit was assessed via the Chi-square differences using the Satorra-Bentler scaled Chi-square $(\Delta S$ $\left.\mathrm{B} \chi^{2}\right)$ and changes in CFI ( $\left.\Delta \mathrm{CFI}\right)$ between the models. The insignificant $\Delta \mathrm{S}-\mathrm{B} \chi^{2}(p>0.05)$ and the less than $-0.01 \Delta \mathrm{CFI}$ between the models indicate an acceptable fit for a more restrictive model (Cheung and Rensvold 2002).

The results of the configural invariance test show a good fit for current data, supporting configural invariance of the two-factor structure of the Grit-S scale across two country samples. Next, I tested for metric invariance of the model by making factor loadings of all grit items invariant across two groups. $\Delta \mathrm{CFI}$ was slightly higher than $-0.01(\Delta \mathrm{CFI}=-0.017)$, and the $\Delta \mathrm{S}-\mathrm{B} \chi^{2}$ was statistically significant $\left(\Delta \mathrm{S}-\mathrm{B} \chi^{2}=50.762, \Delta d f=7, p<0.05\right)$, suggesting that metric invariance is not supported. Based on this result, I tested for partial metric invariance. Consistency item three, "New ideas and projects sometimes distract me from previous ones," in the Korean model was freed, as it showed lower factor loading in the Korean model compared to the US model. $\Delta$ CFI for partial metric invariance model was smaller than -0.01 , and $\Delta \mathrm{S}-\mathrm{B} \chi^{2}$ was not statistically significant $(p>0.05)$, supporting partial metric invariance of the two-factor grit model. In sum, these results suggest that at least a partial metric invariance exists across the two country samples, providing evidence that respondents of current cross-cultural samples tend to interpret and respond to grit items in a relatively similar way.

\subsection{The Construct Validity of the Grit Measures}

Tables 5 and 6 present the results of the hierarchical regression analysis using global grit (Models 1 to 4) and two separate dimensions (Models 5 to 8) to examine the relationship between grit and subjective well-being in each country. Many previous grit studies have used a total grit score without a proper measurement test. To demonstrate what might be omitted if relying solely on the total grit score (which is also not supported by the measurement test in the present study), this paper presents the results of both regressions using the total grit score and separate dimension scores, providing a more substantial understanding of these two approaches. Models 1 and 5 include grit (the overall Grit-S score) and the two dimensions of grit (perseverance and consistency), respectively, and sociodemographic variables. Models 2 and 6 introduce the sense of control, Models 3 and 7 introduce conscientiousness, and Models 4 and 8 include both to assess how much of the variance in subjective well-being is explained by grit measures beyond these two correlates.

Model 1 shows that, on average, a one-unit increase in grit (on a five-point scale) is associated with a 0.563 (the US sample) and a 0.708 point increase (the Korean sample) in subjective well-being (on an 11-point scale), net of sociodemographic variables. This implies that when holding sociodemographic factors constant, American and Korean respondents who report the highest level of grit (scoring 5 on a five-point scale) would report, on average, having $2.252(=0.563 * 5-0.563 * 1)$ and $2.832(=0.708 * 5-0.708 * 1)$ points higher subjective well-being than those with the lowest level of grit (scoring 1 on a five-point scale). Grit explains an additional $2.8 \%$ and $4.0 \%$ of the variance in subjective well-being compared to the baseline model, which includes sociodemographic variables 
Table 5 Regressions of subjective well-being for the US sample

\begin{tabular}{|c|c|c|c|c|c|c|c|c|}
\hline \multirow[t]{2}{*}{ Variable } & \multicolumn{4}{|c|}{ Models with global grit } & \multicolumn{4}{|c|}{ Models with grit dimensions } \\
\hline & Model 1 & Model 2 & Model 3 & Model 4 & Model 5 & Model 6 & Model 7 & Model 8 \\
\hline Age & $\begin{array}{r}-0.008 \\
(0.006)\end{array}$ & $\begin{array}{r}-0.013 * \\
(0.006)\end{array}$ & $\begin{array}{r}-0.011 \\
(0.006)\end{array}$ & $\begin{array}{r}-0.014^{*} \\
(0.006)\end{array}$ & $\begin{array}{r}-0.007 \\
(0.006)\end{array}$ & $\begin{array}{r}-0.012 * \\
(0.006)\end{array}$ & $\begin{array}{r}-0.009 \\
(0.006)\end{array}$ & $\begin{array}{r}-0.012 * \\
(0.006)\end{array}$ \\
\hline Female & $\begin{array}{r}-0.086 \\
(0.172)\end{array}$ & $\begin{array}{r}-0.138 \\
(0.167)\end{array}$ & $\begin{array}{r}-0.139 \\
(0.173)\end{array}$ & $\begin{array}{r}-0.156 \\
(0.168)\end{array}$ & $\begin{array}{r}-0.079 \\
(0.171)\end{array}$ & $\begin{array}{r}-0.131 \\
(0.166)\end{array}$ & $\begin{array}{r}-0.129 \\
(0.172)\end{array}$ & $\begin{array}{r}-0.147 \\
(0.167)\end{array}$ \\
\hline White & $\begin{array}{c}0.043 \\
(0.234)\end{array}$ & $\begin{array}{c}0.063 \\
(0.231)\end{array}$ & $\begin{array}{c}0.039 \\
(0.233)\end{array}$ & $\begin{array}{c}0.061 \\
(0.231)\end{array}$ & $\begin{array}{c}0.068 \\
(0.233)\end{array}$ & $\begin{array}{c}0.087 \\
(0.229)\end{array}$ & $\begin{array}{c}0.064 \\
(0.232)\end{array}$ & $\begin{array}{c}0.085 \\
(0.229)\end{array}$ \\
\hline College & $\begin{array}{c}0.415 * \\
(0.169)\end{array}$ & $\begin{array}{l}0.439 * * \\
(0.161)\end{array}$ & $\begin{array}{l}0.421 * \\
(0.169)\end{array}$ & $\begin{array}{l}0.440 * * \\
(0.161)\end{array}$ & $\begin{array}{c}0.341 * \\
(0.172)\end{array}$ & $\begin{array}{l}0.368 * \\
(0.165)\end{array}$ & $\begin{array}{l}0.348 * \\
(0.172)\end{array}$ & $\begin{array}{c}0.369^{*} \\
(0.165)\end{array}$ \\
\hline Household & $0.154 * * *$ & $0.137 * * *$ & $0.151 * * *$ & $0.136 * * *$ & $0.148 * * *$ & $0.131 * * *$ & $0.145^{* * *}$ & $0.130 * * *$ \\
\hline & $(0.031)$ & $(0.030)$ & $(0.031)$ & $(0.030)$ & $(0.031)$ & $(0.030)$ & $(0.031)$ & $(0.030)$ \\
\hline Married & $\begin{array}{c}0.477 * \\
(0.190)\end{array}$ & $\begin{array}{c}0.472 * \\
(0.185)\end{array}$ & $\begin{array}{c}0.474 * \\
(0.191)\end{array}$ & $\begin{array}{c}0.471 * \\
(0.186)\end{array}$ & $\begin{array}{c}0.468 * \\
(0.189)\end{array}$ & $\begin{array}{c}0.464 * \\
(0.185)\end{array}$ & $\begin{array}{c}0.466^{*} \\
(0.190)\end{array}$ & $\begin{array}{r}0.463 * \\
(0.185)\end{array}$ \\
\hline Religiosity & $\begin{array}{l}0.147 * * * \\
(0.024)\end{array}$ & $\begin{array}{l}0.160 * * * \\
(0.024)\end{array}$ & $\begin{array}{l}0.147 * * * \\
(0.024)\end{array}$ & $\begin{array}{l}0.159 * * * \\
(0.024)\end{array}$ & $\begin{array}{l}0.134 * * * \\
(0.025)\end{array}$ & $\begin{array}{l}0.147 * * * \\
(0.025)\end{array}$ & $\begin{array}{l}0.134 * * * \\
(0.024)\end{array}$ & $\begin{array}{r}0.146 * * * \\
(0.025)\end{array}$ \\
\hline Grit-S & $\begin{array}{l}0.563 * * * \\
(0.137)\end{array}$ & $\begin{array}{c}0.237 \\
(0.154)\end{array}$ & $\begin{array}{c}0.294 \\
(0.178)\end{array}$ & $\begin{array}{c}0.146 \\
(0.179)\end{array}$ & & & & \\
\hline $\begin{array}{l}\text { Grit-persever- } \\
\text { ance }\end{array}$ & & & & & $\begin{array}{l}0.540 * * * \\
(0.102)\end{array}$ & $\begin{array}{l}0.368 * * * \\
(0.109)\end{array}$ & $\begin{array}{l}0.407 * * * \\
(0.121)\end{array}$ & $\begin{array}{l}0.327 * * \\
(0.122)\end{array}$ \\
\hline $\begin{array}{l}\text { Grit-consist- } \\
\text { ency }\end{array}$ & & & & & $\begin{array}{c}0.076 \\
(0.091)\end{array}$ & $\begin{array}{r}-0.075 \\
(0.099)\end{array}$ & $\begin{array}{r}-0.045 \\
(0.103)\end{array}$ & $\begin{array}{r}-0.113 \\
(0.107)\end{array}$ \\
\hline Sense of control & & $\begin{array}{l}0.867 * * * \\
(0.172)\end{array}$ & & $\begin{array}{l}0.831 * * * \\
(0.179)\end{array}$ & & $\begin{array}{l}0.853 * * * \\
(0.172)\end{array}$ & & $\begin{array}{r}0.822 * * * \\
(0.178)\end{array}$ \\
\hline $\begin{array}{l}\text { Conscientious- } \\
\text { ness }\end{array}$ & & & $\begin{array}{l}0.365^{*} \\
(0.166)\end{array}$ & $\begin{array}{c}0.141 \\
(0.169)\end{array}$ & & & $\begin{array}{l}0.343 * \\
(0.167)\end{array}$ & $\begin{array}{c}0.122 \\
(0.169)\end{array}$ \\
\hline Constant & $\begin{array}{l}3.333 * * * \\
(0.555)\end{array}$ & $\begin{array}{l}4.270 * * * \\
(0.578)\end{array}$ & $\begin{array}{l}3.023 * * * \\
(0.575)\end{array}$ & $\begin{array}{l}4.112 * * * \\
(0.620)\end{array}$ & $\begin{array}{l}3.069 * * * \\
(0.564)\end{array}$ & $\begin{array}{l}4.002 * * * \\
(0.587)\end{array}$ & $\begin{array}{l}2.784 * * * \\
(0.579)\end{array}$ & $\begin{array}{r}3.867 * * * \\
(0.624)\end{array}$ \\
\hline $\mathrm{R}^{2}$ & 0.229 & 0.269 & 0.236 & 0.270 & 0.245 & 0.284 & 0.251 & 0.285 \\
\hline Change in $\mathrm{R}^{2}$ & 0.028 & 0.040 & 0.007 & 0.041 & 0.044 & 0.039 & 0.006 & 0.040 \\
\hline
\end{tabular}

Note: Unstandardized coefficients appear above robust standard errors in parentheses. Changes in $\mathrm{R}^{2}$ of Models 1 and 5 (in bold) are calculated using $\mathrm{R}^{2}$ of the baseline model, which includes sociodemographic variables only. $\mathrm{R}^{2}$ Changes of Models 2 to 4 and Models 6 to 8 are calculated using $\mathrm{R}^{2}$ of Models 1 and 5 , respectively

$* * * p<0.001, * * p<0.01, * p<0.05$ (two-tailed tests)

only (results not shown but available upon request) in the US and Korean samples, respectively. This strong positive effect of having grit on American respondents' subjective wellbeing is reduced by 58 percent ( $b=0.237$; Model 2$)$ and 48 percent $(b=0.294$; Model 3 ) when sense of control and conscientiousness are introduced, and adding both correlates reduces grit's estimate by 74 percent $(b=0.146$; Model 4$)$. In the Korean sample, introducing the sense of control and conscientiousness reduces the effect of grit on subjective 
Table 6 Regressions of subjective well-being for the Korean sample

\begin{tabular}{|c|c|c|c|c|c|c|c|c|}
\hline \multirow[t]{2}{*}{ Variable } & \multicolumn{4}{|c|}{ Models with global grit } & \multicolumn{4}{|c|}{ Models with grit dimensions } \\
\hline & Model 1 & Model 2 & Model 3 & Model 4 & Model 5 & Model 6 & Model 7 & Model 8 \\
\hline Age & $\begin{array}{r}-0.020 * \\
(0.008)\end{array}$ & $\begin{array}{r}-0.018 * \\
(0.008)\end{array}$ & $\begin{array}{c}-0.028^{* * *} \\
(0.008)\end{array}$ & $\begin{array}{c}-0.025^{* * *} \\
(0.007)\end{array}$ & $\begin{array}{r}-0.019 * \\
(0.008)\end{array}$ & $\begin{array}{r}-0.017^{*} \\
(0.008)\end{array}$ & $\begin{array}{c}-0.028 * * * \\
(0.008)\end{array}$ & $\begin{array}{c}-0.025^{* *} \\
(0.007)\end{array}$ \\
\hline Female & $\begin{array}{r}-0.004 \\
(0.178)\end{array}$ & $\begin{array}{c}0.036 \\
(0.169)\end{array}$ & $\begin{array}{c}0.010 \\
(0.170)\end{array}$ & $\begin{array}{c}0.036 \\
(0.165)\end{array}$ & $\begin{array}{c}0.005 \\
(0.178)\end{array}$ & $\begin{array}{c}0.039 \\
(0.168)\end{array}$ & $\begin{array}{c}0.017 \\
(0.169)\end{array}$ & $\begin{array}{c}0.040 \\
(0.165)\end{array}$ \\
\hline College & $\begin{array}{c}0.161 \\
(0.183)\end{array}$ & $\begin{array}{c}0.193 \\
(0.175)\end{array}$ & $\begin{array}{r}-0.092 \\
(0.186)\end{array}$ & $\begin{array}{r}-0.005 \\
(0.184)\end{array}$ & $\begin{array}{c}0.169 \\
(0.184)\end{array}$ & $\begin{array}{c}0.196 \\
(0.176)\end{array}$ & $\begin{array}{r}-0.084 \\
(0.187)\end{array}$ & $\begin{array}{r}-0.003 \\
(0.185)\end{array}$ \\
\hline $\begin{array}{l}\text { Household } \\
\text { income }\end{array}$ & $\begin{array}{l}0.055 \\
(0.030)\end{array}$ & $\begin{array}{l}0.039 \\
(0.029)\end{array}$ & $\begin{array}{l}0.047 \\
(0.029)\end{array}$ & $\begin{array}{c}0.037 \\
(0.028)\end{array}$ & $\begin{array}{l}0.054 \\
(0.030)\end{array}$ & $\begin{array}{c}0.039 \\
(0.029)\end{array}$ & $\begin{array}{c}0.045 \\
(0.029)\end{array}$ & $\begin{array}{c}0.036 \\
(0.028)\end{array}$ \\
\hline Married & $\begin{array}{l}0.806^{* * *} \\
(0.211)\end{array}$ & $\begin{array}{l}0.740^{* * *} \\
(0.204)\end{array}$ & $\begin{array}{l}0.747 * * * \\
(0.204)\end{array}$ & $\begin{array}{l}0.712^{* * *} \\
(0.200)\end{array}$ & $\begin{array}{l}0.810^{* * *} \\
(0.212)\end{array}$ & $\begin{array}{l}0.742 * * * \\
(0.205)\end{array}$ & $\begin{array}{l}0.751^{* * *} \\
(0.204)\end{array}$ & $\begin{array}{l}0.715 \text { *** } \\
(0.200)\end{array}$ \\
\hline Religiosity & $\begin{array}{l}0.120^{* * *} \\
(0.030)\end{array}$ & $\begin{array}{l}0.126^{* * *} \\
(0.029)\end{array}$ & $\begin{array}{l}0.146^{* * *} \\
(0.029)\end{array}$ & $\begin{array}{l}0.144 * * * \\
(0.029)\end{array}$ & $\begin{array}{l}0.119 * * * \\
(0.030)\end{array}$ & $\begin{array}{l}0.125^{* * *} \\
(0.029)\end{array}$ & $\begin{array}{l}0.145^{* * *} \\
(0.029)\end{array}$ & $\begin{array}{l}0.143 \text { *** } \\
(0.029)\end{array}$ \\
\hline Grit-S & $\begin{array}{l}0.708^{* * *} \\
(0.199)\end{array}$ & $\begin{array}{c}0.459 * \\
(0.186)\end{array}$ & $\begin{array}{c}0.144 \\
(0.174)\end{array}$ & $\begin{array}{c}0.097 \\
(0.166)\end{array}$ & & & & \\
\hline $\begin{array}{l}\text { Grit-perse- } \\
\text { verance }\end{array}$ & & & & & $\begin{array}{l}0.453 * * * \\
(0.135)\end{array}$ & $\begin{array}{l}0.266^{*} \\
(0.129)\end{array}$ & $\begin{array}{l}0.159 \\
(0.120)\end{array}$ & $\begin{array}{c}0.091 \\
(0.116)\end{array}$ \\
\hline $\begin{array}{l}\text { Grit-con- } \\
\text { sistency }\end{array}$ & & & & & $\begin{array}{l}0.243 \\
(0.138)\end{array}$ & $\begin{array}{l}0.190 \\
(0.130)\end{array}$ & $\begin{array}{r}-0.023 \\
(0.132)\end{array}$ & $\begin{array}{c}0.002 \\
(0.128)\end{array}$ \\
\hline $\begin{array}{l}\text { Sense of } \\
\text { control }\end{array}$ & & $\begin{array}{l}1.348 * * * \\
(0.209)\end{array}$ & & $\begin{array}{l}1.010 * * * \\
(0.220)\end{array}$ & & $\begin{array}{l}1.339^{* * * *} \\
(0.208)\end{array}$ & & $\begin{array}{l}0.999 * * * \\
(0.220)\end{array}$ \\
\hline $\begin{array}{l}\text { Conscien- } \\
\text { tiousness }\end{array}$ & & & $\begin{array}{l}1.174 * * * \\
(0.191)\end{array}$ & $\begin{array}{l}0.883 * * * \\
(0.205)\end{array}$ & & & $\begin{array}{l}1.170 \text { *** } \\
(0.190)\end{array}$ & $\begin{array}{l}0.884 * * * \\
(0.205)\end{array}$ \\
\hline Constant & $\begin{array}{l}3.083^{* * *} \\
(0.646)\end{array}$ & $\begin{array}{l}3.291 * * * \\
(0.619)\end{array}$ & $\begin{array}{r}1.342 * \\
(0.651)\end{array}$ & $\begin{array}{l}1.930 * * \\
(0.675)\end{array}$ & $\begin{array}{l}3.085 * * * \\
(0.644)\end{array}$ & $\begin{array}{l}3.291 \text { *** } \\
(0.620)\end{array}$ & $\begin{array}{c}1.350 * \\
(0.648)\end{array}$ & $\begin{array}{l}1.927 * * \\
(0.675)\end{array}$ \\
\hline $\mathrm{R}^{2}$ & 0.148 & 0.224 & 0.224 & 0.262 & 0.150 & 0.224 & 0.226 & 0.262 \\
\hline $\begin{array}{c}\text { Change in } \\
\mathrm{R}^{2}\end{array}$ & 0.040 & 0.076 & 0.076 & 0.114 & 0.042 & 0.074 & 0.076 & 0.112 \\
\hline
\end{tabular}

Note: Unstandardized coefficients appear above robust standard errors in parentheses. Changes in $\mathrm{R}^{2}$ of Models 1 and 5 (in bold) are calculated using $\mathrm{R}^{2}$ of the baseline model, which includes sociodemographic variables only. $\mathrm{R}^{2}$ Changes of Models 2 to 4 and Models 6 to 8 are calculated using $\mathrm{R}^{2}$ of Models 1 and 5 , respectively

$* * * p<0.001, * * p<0.01, * p<0.05$ (two-tailed tests)

well-being by 35 percent ( $b=0.459$; Model 2) and 80 percent $(b=0.144$; Model 3$)$, respectively, and the effect of grit is reduced by 86 percent $(b=0.097$; Model 4$)$ when both variables are added simultaneously. I find little evidence to corroborate prior studies that argued for the distinctive utility of the global grit over conscientiousness in predicting subjective well-being; the positive effect of grit on subjective well-being is reduced by half in the US sample and by more than two-thirds in the Korean sample when conscientiousness is introduced. 
The analysis using the dimensions of grit shows slightly different results. A one-unit increase in perseverance (on a five-point scale), on average, is associated with a 0.540 (the US sample) and a 0.453 point increase (the Korean sample) in subjective well-being (on an 11-point scale), holding sociodemographic variables constant (Model 5). Respondents who report the highest level of perseverance (scored 5 on a five-point scale) would report on average 2.16 (in the US sample) and 1.812 (in the Korean sample) points higher subjective well-being than those with the lowest level of perseverance (scored 1 on a five-point scale), net of sociodemographic factors. By contrast, consistency appears to be less helpful for subjective well-being than perseverance in both country samples $(b=0.076$ for the US sample and 0.243 for the Korean sample). Introducing sense of control (Model 6) and conscientiousness (Model 7) in the US sample reduces the benefit of having higher perseverance by 32 percent $(b=0.368)$ and 25 percent $(b=0.407)$, slightly to a lesser degree compared to the models using global grit. Even when adding both variables simultaneously, the advantageous effect of perseverance remains substantially important in explaining the variance of subjective well-being, showing a 39 percent decrease in the estimate $(b=0.327$; Model 8). Adding the sense of control and conscientiousness reduces the effect of perseverance on subjective well-being by 41 percent $(b=0.266$; Model 6$)$ and 65 percent $(b=0.159$; Model 7), respectively, and by 80 percent $(b=0.091$; Model 8$)$ when both variables are added in the Korean sample. The consistency dimension of grit adds little to our understanding of one's subjective well-being beyond the two correlates $(b=-0.113$ in the US sample and 0.002 in the Korean sample; Model 8). These results extend prior findings that show the unique benefit of perseverance and a less relevant role of consistency in subjective well-being (e.g., Datu et al. 2016 using their Filipino student sample) in the US and Korean adult samples. Relying on the aggregated grit score might fail to capture the unique role of the perseverance dimension in understanding subjective well-being beyond existing psychological measures.

These findings support the distinctive utility of perseverance beyond the sense of control and conscientiousness for subjective well-being in the current US sample. While global grit and perseverance contribute to explaining the variance in subjective well-being in the current Korean sample controlling for the sense of control, their role becomes limited when taking conscientiousness into account: the estimates of global grit and perseverance are significantly reduced (by 80 percent in Model 3 and 65 percent in Model 7) when conscientiousness is added, implying that the global grit and perseverance measures largely overlap with conscientiousness in accounting for subjective well-being in the current Korean sample.

\section{Discussion and Conclusion}

Prior scholarship mostly relied on the overall grit score, often without measurement tests, and used convenience samples collected in a single country (see Disabato et al. 2019 for a review). In addition, only a few studies demonstrate the utility of grit beyond its psychological correlates, hindering researchers from properly evaluating the utility of grit as a measure that explains the incremental variance in outcome variables. Therefore, this study aimed to assess grit's measurement and distinctive utility in explaining subjective well-being beyond the existing psychological measures (i.e., sense of control and conscientiousness) that relate to both grit and subjective well-being and widen the cross-cultural 
discussion by examining grit in both the US and South Korean contexts using more general samples.

Findings of the measurement test support the two-factor structure of grit in both country samples, suggesting that grit is better understood as a construct consisting of two distinct, but related dimensions, the perseverance of effort and consistency of interest, rather than as a global construct. This result is consistent with previous studies, which documented a lack of or weak correlation between the two lower-order dimensions of grit (e.g., Datu et al. 2016), extending it to the South Korean context. The two-factor model of grit achieved partial metric invariance, providing evidence that the US and Korean respondents in this study tend to respond to grit items in a relatively similar way.

The regression analysis found that grittier people are happier and more satisfied with life than others in both samples, controlling for sociodemographic variables. Perseverance achieved the distinctive utility in explaining the subjective well-being of Americans and Koreans beyond their sense of control, a traditional measure of subjective agency. Despite the presumed similarity in valuing hard work in both countries (e.g., the "American dream" and Confucian tradition), the distinctive role of perseverance beyond conscientiousness was found only in the American sample. By contrast, the variance in subjective well-being explained by perseverance seems to largely overlap with that of conscientiousness in the Korean model. Traditionally, collectivistic cultures often put more emphasis on being attentive to others and the environment, and the pursuit of personal goals is relatively less valued in collectivistic than in individualistic settings (e.g., Datu et al. 2016). This may point out potential culturally bound interpretations of grit's role that are important for researchers to approach cautiously. Grit's perseverance, which may serve as the ability to pursue personal goals via hard work, adds little to the understanding of Koreans' subjective well-being in the collectivistic setting beyond conscientiousness, which taps into the similar aspect of one's psychological profile. Personality measures of conscientiousness might be sufficient for explaining variations in subjective well-being in this context. This set of mixed findings across different samples supports the argument of Ion et al. (2017), which suggests that future studies on the relationship between grit and outcomes must include grit's correlates, particularly conscientiousness, in their models to demonstrate grit's validity.

Comparing the results using the overall grit score with those using grit dimensions separately informs us that the aggregated grit score might conceal the different incremental validity of two dimensions in understanding subjective well-being, specifically the role of grit's perseverance dimension in the United States. Perseverance is important in one's level of subjective well-being, but having consistent interests seems to be less relevant to subjective well-being in both countries. This finding echoes that of Disabato et al. (2019) using the Grit-O scale, suggesting that global grit may hide the weak or null relationships between consistency of interest and subjective well-being. Too much unwarranted passion for sticking to one goal in the face of repeated failures might not be helpful for one's subjective well-being. This calls for further research on the utility of the current measure of the consistency dimension.

Several limitations of this study should be discussed. One of the limitations stems from its sample. Respondents of this study were those who voluntarily registered for the panel to participate in the online survey, which could provide biased data. This study does not intend to generalize its results to other populations beyond the current samples. This study seeks to examine the psychometric property and the relationship of grit with its psychological correlates using broader samples collected from two countries, given that prior research on grit often relied on narrower convenience samples in a single nation. Another limitation 
comes from the cross-sectional design of current data, which makes it difficult to clarify the causality of the relationships. Identifying a causal mechanism is not the main intention of the present study. While this study assumes that grit is predictive of subjective well-being based on previous works and theoretical justification, it is possible that the causal ordering of grit and subjective well-being operates in the opposite direction, such that one's subjective well-being encourages individuals to perceive one's level of grit higher than others with worse subjective well-being. In addition, the cross-sectional design does not allow us to address concerns regarding the inclusion or exclusion of college and household income in our regression of subjective well-being (i.e., overcontrol bias or confounding bias). This paper presents both results - one with these variables included in the main text and the other without these variables in the "Appendix", to help readers better evaluate the results. The results did not show significant differences except for slightly higher estimates of grit measures when excluding college and household income. Future research with longitudinal data should disentangle the issue of causality and potential biases regarding the choice of control variables.

The findings suggest that relying on global grit, which aggregates the scores of the two dimensions, may conceal a less relevant role of the consistency dimension and a significant, unique role of the perseverance dimension in understanding subjective well-being. As discussed, adhering to one goal despite multiple failures might not be conducive to subjective well-being. Rather, the ability to sustain persistent efforts to achieve the desired goal (perseverance of effort) and subjective beliefs about agency in life (sense of control) can help individuals feel happier and more satisfied with their life. These findings corroborate those of prior studies, which show a stronger predictive power of the perseverance dimension than the consistency dimension in understanding subjective well-being and suggest examining the role of perseverance and consistency separately (e.g., Datu et al. 2016; Disabato et al. 2019). Future research on grit should examine grit's factor-structure and the relationship between grit and subjective well-being based on the measurement test and consider reporting the results of the two dimensions separately (based on the results of measurement test) to clarify the role of grit in shaping one's subjective well-being.

Acknowledgements This research is based in part on the author's dissertation submitted in partial fulfillment of the PhD requirements at the University of Iowa. I would like to thank Steven Hitlin, Jennifer Glanville, and Jani Erola for enormous support, helpful comments, and suggestions on earlier versions of this work. I would like to express appreciation to Graduate College and the College of Liberal Arts \& Sciences at the University of Iowa for supporting my dissertation research through the Ballard and Seashore Dissertation Fellowship and the CLAS Dissertation Writing Fellowship.

Funding This research was supported by the Society for the Psychological Study of Social Issues (SPSSI), the Graduate \& Professional Student Government (GPSG), the Center for Asian and Pacific Studies (CAPS), the Department of Sociology at the University of Iowa. This work was also supported by the Academy of Finland Flagship INVEST [grant number 320162].

\section{Compliance with Ethical Standards}

Conflict of interest The author declares that she has no conflict of interest.

Ethical Approval This research received approval from the Institutional Review Board of the University of Iowa.

Informed Consent Informed consent was obtained from all individual participants included in the study, following the ethical guidelines of the University of Iowa. 
Open Access This article is licensed under a Creative Commons Attribution 4.0 International License, which permits use, sharing, adaptation, distribution and reproduction in any medium or format, as long as you give appropriate credit to the original author(s) and the source, provide a link to the Creative Commons licence, and indicate if changes were made. The images or other third party material in this article are included in the article's Creative Commons licence, unless indicated otherwise in a credit line to the material. If material is not included in the article's Creative Commons licence and your intended use is not permitted by statutory regulation or exceeds the permitted use, you will need to obtain permission directly from the copyright holder. To view a copy of this licence, visit http://creativecommons.org/licenses/by/4.0/.

\section{Appendix}

See Tables 7 and 8 .

Table 7 Regressions of subjective well-being for the US sample

\begin{tabular}{|c|c|c|c|c|c|c|c|c|}
\hline \multirow[t]{2}{*}{ Variable } & \multicolumn{4}{|c|}{ Models with global grit } & \multicolumn{4}{|c|}{ Models with grit dimensions } \\
\hline & Model 1 & Model 2 & Model 3 & Model 4 & Model 5 & Model 6 & Model 7 & Model 8 \\
\hline Age & $\begin{array}{r}-0.012 * \\
(0.006)\end{array}$ & $\begin{array}{c}-0.017 * * \\
(0.006)\end{array}$ & $\begin{array}{r}-0.015^{*} \\
(0.006)\end{array}$ & $\begin{array}{c}-0.018^{* *} \\
(0.006)\end{array}$ & $\begin{array}{r}-0.010 \\
(0.006)\end{array}$ & $\begin{array}{c}-0.015^{* *} \\
(0.006)\end{array}$ & $\begin{array}{r}-0.012 * \\
(0.006)\end{array}$ & $\begin{array}{c}-0.016^{* *} \\
(0.006)\end{array}$ \\
\hline Female & $\begin{array}{r}-0.361 * \\
(0.170)\end{array}$ & $\begin{array}{r}-0.397 * \\
(0.165)\end{array}$ & $\begin{array}{r}-0.417 * \\
(0.170)\end{array}$ & $\begin{array}{r}-0.417 * \\
(0.166)\end{array}$ & $\begin{array}{r}-0.327 \\
(0.170)\end{array}$ & $\begin{array}{r}-0.363^{*} \\
(0.164)\end{array}$ & $\begin{array}{r}-0.379 * \\
(0.170)\end{array}$ & $\begin{array}{r}-0.380 * \\
(0.166)\end{array}$ \\
\hline White & $\begin{array}{c}0.176 \\
(0.235)\end{array}$ & $\begin{array}{c}0.183 \\
(0.233)\end{array}$ & $\begin{array}{c}0.169 \\
(0.234)\end{array}$ & $\begin{array}{c}0.180 \\
(0.233)\end{array}$ & $\begin{array}{c}0.200 \\
(0.233)\end{array}$ & $\begin{array}{c}0.206 \\
(0.231)\end{array}$ & $\begin{array}{c}0.192 \\
(0.232)\end{array}$ & $\begin{array}{c}0.203 \\
(0.231)\end{array}$ \\
\hline Married & $\begin{array}{l}0.965^{* * * *} \\
(0.179)\end{array}$ & $\begin{array}{l}0.912 \text { *** } \\
(0.173)\end{array}$ & $\begin{array}{l}0.953^{* * *} \\
(0.178)\end{array}$ & $\begin{array}{l}0.909^{* * *} \\
(0.172)\end{array}$ & $\begin{array}{l}0.916 * * * \\
(0.178)\end{array}$ & $\begin{array}{l}0.866^{* * *} \\
(0.172)\end{array}$ & $\begin{array}{l}0.906 * * * \\
(0.177)\end{array}$ & $\begin{array}{l}0.865 * * * \\
(0.172)\end{array}$ \\
\hline Religiosity & $\begin{array}{l}0.139 * * * \\
(0.025)\end{array}$ & $\begin{array}{l}0.153 * * * \\
(0.025)\end{array}$ & $\begin{array}{l}0.139 * * * \\
(0.025)\end{array}$ & $\begin{array}{l}0.152^{* * *} \\
(0.025)\end{array}$ & $\begin{array}{l}0.123 * * * \\
(0.026)\end{array}$ & $\begin{array}{l}0.138 * * * \\
(0.025)\end{array}$ & $\begin{array}{l}0.123 * * * \\
(0.025)\end{array}$ & $\begin{array}{l}0.137 * * * \\
(0.025)\end{array}$ \\
\hline Grit-S & $\begin{array}{l}0.596 * * * \\
(0.138)\end{array}$ & $\begin{array}{c}0.233 \\
(0.154)\end{array}$ & $\begin{array}{c}0.291 \\
(0.179)\end{array}$ & $\begin{array}{c}0.130 \\
(0.179)\end{array}$ & & & & \\
\hline $\begin{array}{l}\text { Grit-persever- } \\
\text { ance }\end{array}$ & & & & & $\begin{array}{l}0.625 * * * \\
(0.108)\end{array}$ & $\begin{array}{l}0.432 * * * \\
(0.114)\end{array}$ & $\begin{array}{l}0.477 * * * \\
(0.126)\end{array}$ & $\begin{array}{l}0.387 * * \\
(0.126)\end{array}$ \\
\hline $\begin{array}{l}\text { Grit-consist- } \\
\text { ency }\end{array}$ & & & & & $\begin{array}{l}0.036 \\
(0.096)\end{array}$ & $\begin{array}{r}-0.128 \\
(0.105)\end{array}$ & $\begin{array}{r}-0.099 \\
(0.110)\end{array}$ & $\begin{array}{r}-0.170 \\
(0.113)\end{array}$ \\
\hline $\begin{array}{l}\text { Sense of } \\
\text { control }\end{array}$ & & $\begin{array}{l}0.953^{* * * *} \\
(0.174)\end{array}$ & & $\begin{array}{l}0.912 * * * \\
(0.180)\end{array}$ & & $\begin{array}{l}0.930^{* * *} \\
(0.174)\end{array}$ & & $\begin{array}{l}0.895 * * * \\
(0.180)\end{array}$ \\
\hline $\begin{array}{l}\text { Conscientious- } \\
\text { ness }\end{array}$ & & & $\begin{array}{l}0.412 * \\
(0.171)\end{array}$ & $\begin{array}{l}0.161 \\
(0.172)\end{array}$ & & & $\begin{array}{l}0.381 * \\
(0.173)\end{array}$ & $\begin{array}{l}0.136 \\
(0.173)\end{array}$ \\
\hline Constant & $\begin{array}{l}4.325^{* * *} \\
(0.542)\end{array}$ & $\begin{array}{l}5.273^{* * *} \\
(0.557)\end{array}$ & $\begin{array}{l}3.958 * * * \\
(0.560)\end{array}$ & $\begin{array}{l}5.089 * * * \\
(0.601)\end{array}$ & $\begin{array}{l}3.898 * * * \\
(0.556)\end{array}$ & $\begin{array}{l}4.844 * * * \\
(0.571)\end{array}$ & $\begin{array}{l}3.569 * * * \\
(0.568)\end{array}$ & $\begin{array}{l}4.691 * * * \\
(0.609)\end{array}$ \\
\hline $\mathrm{R}^{2}$ & 0.165 & 0.214 & 0.174 & 0.216 & 0.191 & 0.238 & 0.199 & 0.239 \\
\hline Change in $\mathrm{R}^{2}$ & 0.032 & 0.049 & 0.009 & 0.051 & 0.058 & 0.047 & 0.008 & 0.048 \\
\hline
\end{tabular}

Note Unstandardized coefficients appear above robust standard errors in parentheses. Changes in $\mathrm{R}^{2}$ of Models 1 and 5 (in bold) are calculated using $\mathrm{R}^{2}$ of the baseline model, which includes sociodemographic variables only. $\mathrm{R}^{2}$ Changes of Models 2 to 4 and Models 6 to 8 are calculated using $\mathrm{R}^{2}$ of Models 1 and 5 , respectively

$* * * p<0.001$, ** $p<0.01, * p<0.05$ (two-tailed tests) 


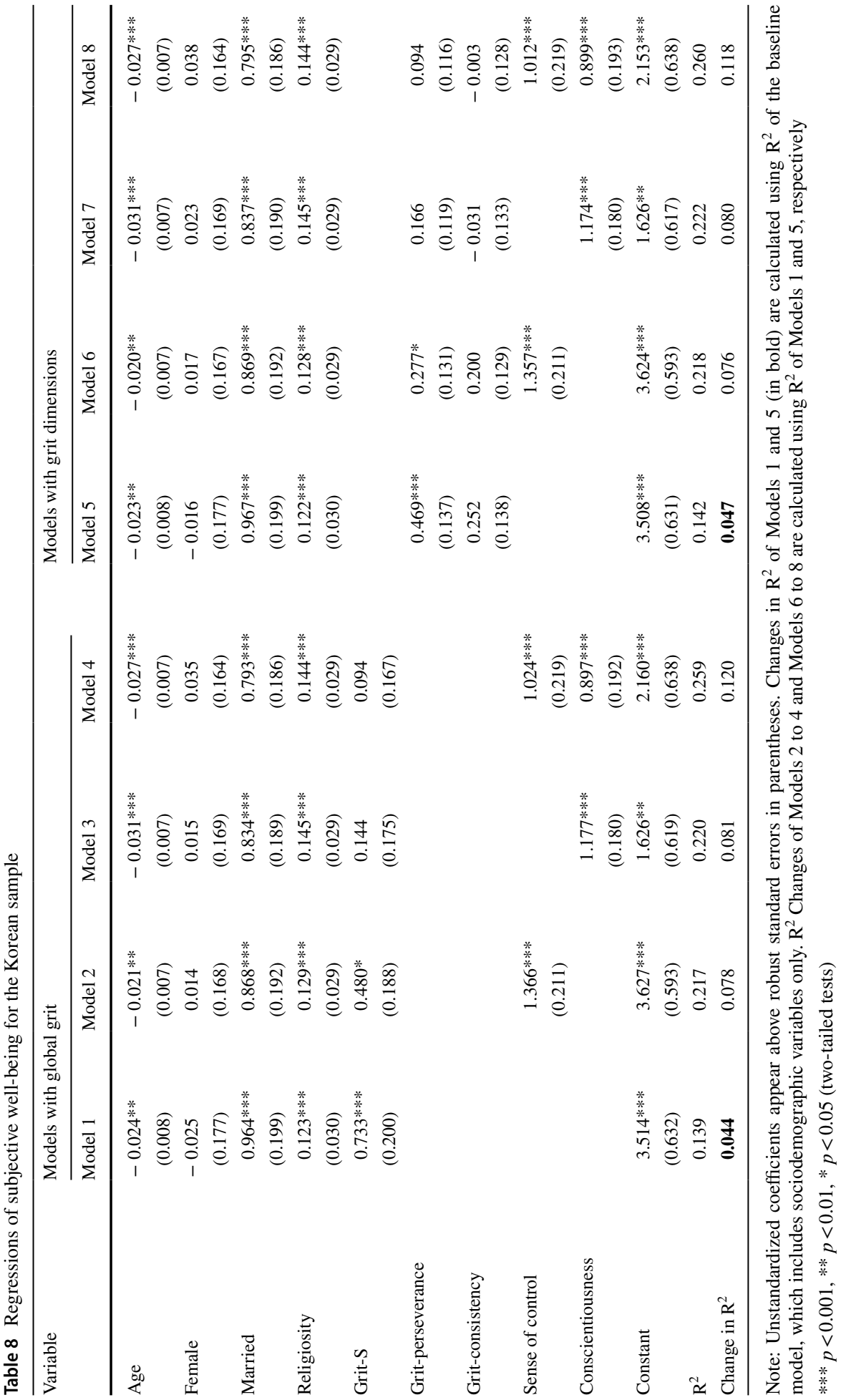




\section{References}

Abuhassàn, A., \& Bates, T. C. (2015). Grit. Journal of Individual Differences, 36(4), 205-214.

Bentler, P. M. (1990). Comparative fit indexes in structural models. Psychological Bulletin, 107, $238-246$.

Blalock, D. V., Young, K. C., \& Kleiman, E. M. (2015). Stability amidst turmoil: Grit buffers the effects of negative life events on suicidal ideation. Psychiatry Research, 228(3), 781-784.

Boas, T. C., Christenson, D. P., \& Glick, D. M. (2018). Recruiting large online samples in the United States and India: Facebook, Mechanical Turk, and Qualtrics. Political Science Research and Methods, 8(2), 1-19.

Bowman, N. A., Hill, P. L., Denson, N., \& Bronkema, R. (2015). Keep on truckin' or stay the course? Exploring grit dimensions as differential predictors of educational achievement, satisfaction, and intentions. Social Psychological and Personality Science, 6(6), 639-645.

Brislin, R. W. (1970). Back-translation for cross-cultural research. Journal of Cross-Cultural Psychology, 1(3), 185-216.

Cheung, G. W., \& Rensvold, R. B. (2002). Evaluating goodness-of-fit indexes for testing measurement invariance. Structural Equation Modeling, 9(2), 233-255.

Credé, M., Tynan, M. C., \& Harms, P. D. (2017). Much ado about grit: A meta-analytic synthesis of the grit literature. Journal of Personality and Social Psychology, 113(3), 492-511.

Datu, J. A. D., King, R. B., Valdez, J. P. M., \& Eala, M. C. M. (2019). Grit is associated with lower depression via meaning in life among Filipino high school students. Youth \& Society, 51(6), 865-876.

Datu, J. A., Valdez, J. P. M., \& King, R. B. (2016). Perseverance counts but consistency does not! Validating the short grit scale in a collectivist setting. Current Psychology, 35(1), 121-130.

Deary, I. J., Weiss, A., \& David Batty, G. (2010). Intelligence and personality as predictors of illness and death: How researchers in differential psychology and chronic disease epidemiology are collaborating to understand and address health inequalities. Psychological Science in the Public Interest, 11(2), 53-79.

Delhey, J., \& Dragolov, G. (2014). Why inequality makes Europeans less happy: The role of distrust, status anxiety, and perceived conflict. European Sociological Review, 30(2), 151-165.

Diener, E. (2006). Guidelines for national indicators of subjective well-being and ill-being. Journal of Happiness Studies, 7(4), 397-404.

Diener, E., Napa Scollon, C., \& Lucas, R. E. (2009). The evolving concept of subjective well-being: The multifaceted nature of happiness. In E. Diener (Ed.), Assessing well-being (pp. 67-100). Berlin: Springer.

Diener, E., Napa-Scollon, C., Oishi, S., Dzokoto, V., \& Suh, E. M. (2000). Positivity and the construction of life satisfaction judgments: Global happiness is not the sum of its parts. Journal of Happiness Studies, $1(2), 159-176$.

Diener, E., Suh, E. M., Lucas, R. E., \& Smith, H. L. (1999). Subjective well-being: Three decades of progress. Psychological Bulletin, 125(2), 276-302.

Disabato, D. J., Goodman, F. R., \& Kashdan, T. B. (2019). Is grit relevant to well-being and strengths? Evidence across the globe for separating perseverance of effort and consistency of interests. Journal of Personality, 87(2), 194-211.

Djupe, P. A., Neiheisel, J. R., \& Sokhey, A. E. (2018). Reconsidering the role of politics in leaving religion: The importance of affiliation. American Journal of Political Science, 62(1), 161-175.

Duckworth, A. L., Kirby, T. A., Tsukayama, E., Berstein, H., \& Anders Ericsson, K. (2011). Deliberate practice spells success: Why grittier competitors triumph at the National Spelling Bee. Social Psychological and Personality Science, 2(2), 174-181.

Duckworth, A. L., Peterson, C., Matthews, M. D., \& Kelly, D. R. (2007). Grit: Perseverance and passion for long-term goals. Journal of Personality and Social Psychology, 92(6), 1087-1101.

Duckworth, A. L., \& Quinn, P. D. (2009). Development and validation of the Short Grit Scale (Grit-S). Journal of Personality Assessment, 91(2), 166-174.

Eskreis-Winkler, L., Shulman, E. P., Beal, S. A., \& Duckworth, A. L. (2014). The grit effect: Predicting retention in the military, the workplace, school and marriage. Frontiers in Psychology, 5(36), 1-12.

Goodman, F. R., Disabato, D. J., Kashdan, T. B., \& Kauffman, S. B. (2018). Measuring well-being: A comparison of subjective well-being and PERMA. Journal of Positive Psychology, 13(4), 321-332.

Hill, P. L., \& Jackson, J. J. (2016). The invest-and-accrue model of conscientiousness. Review of General Psychology, 20(2), 141-154.

Hofstede, G. (1980). Culture's consequences: International differences in work-related values. CA: Sage.

Hu, L.-t., \& Bentler, P. M. (1999). Cutoff criteria for fit indexes in covariance structure analysis: Conventional criteria versus new alternatives. Structural Equation Modeling: A Multidisciplinary Journal, $6(1), 1-55$. 
Hwang, M. H., Lim, H. J., \& Ha, H. S. (2018). Effects of grit on the academic success of adult female students at Korean Open University. Psychological Reports, 121(4), 705-725.

Ion, A., Mindu, A., \& Gorbănescu, A. (2017). Grit in the workplace: Hype or ripe? Personality and Individual Differences, 111, 163-168.

Ivcevic, Z., \& Brackett, M. (2014). Predicting school success: Comparing conscientiousness, grit, and emotion regulation ability. Journal of Research in Personality, 52, 29-36.

John, O. P., \& Srivastava, S. (1999). The big five trait taxonomy: History, measurement, and theoretical perspectives. In L. A. Pervin \& O. P. John (Eds.), Handbook of personality: Theory and research (pp. 102-138). New York: The Guilford Press.

Johnson, R., Harkins, K., Cary, M., Sankar, P., \& Karlawish, J. (2015). The relative contributions of disease label and disease prognosis to Alzheimer's Stigma: A Vignette-based experiment. Social Science and Medicine, 143, 117-127.

Kim, A. E., \& Park, G.-s. (2003). Nationalism, Confucianism, work ethic and industrialization in South Korea. Journal of Contemporary Asia, 33(1), 37-49.

Kleiman, E. M., Adams, L. M., Kashdan, T. B., \& Riskind, J. H. (2013). Gratitude and grit indirectly reduce risk of suicidal ideations by enhancing meaning in life: Evidence for a mediated moderation model. Journal of Research in Personality, 47(5), 539-546.

Kotov, R., Gamez, W., Schmidt, F., \& Watson, D. (2010). Linking "Big" personality traits to anxiety, depressive, and substance use disorders: A meta-analysis. Psychological Bulletin, 136(5), 768-821.

Kwon, H. W. (2017). The sociology of grit: Exploring grit as a sociological variable and its potential role in social stratification. Sociology Compass, 11(12), e12544.

Lachman, M. E., \& Weaver, S. L. (1998). The sense of control as a moderator of social class differences in health and well-being. Journal of Personality and Social Psychology, 74(3), 763-773.

Lee, W. W. S. (2017). Relationships among grit, academic performance, perceived academic failure, and stress in associate degree students. Journal of Adolescence, 60, 148-152.

Linton, M. J., Dieppe, P., \& Medina-Lara, A. (2016). Review of 99 self-report measures for assessing wellbeing in adults: Exploring dimensions of well-being and developments over time. British Medical Journal Open, 6, e010641.

Lyubomirsky, S., \& Lepper, H. S. (1999). A measure of subjective happiness: Preliminary reliability and construct validation. Social Indicators Research, 46(2), 137-155.

Mirowsky, J., \& Ross, C. E. (1991). Eliminating defense and agreement bias from measures of the sense of control: A 2 X 2 index. Social Psychology Quarterly, 54(2), 127-145.

Mirowsky, J., \& Ross, C. E. (1998). Education, personal control, lifestyle and health: A human capital hypothesis. Research on Aging, 20(4), 415-449.

O’Neal, C. R., Espino, M. M., Goldthrite, A., Morin, M. F., Weston, L., Hernandez, P., et al. (2016). Grit under duress: Stress, strengths, and academic success among non-citizen and citizen Latina/O firstgeneration college students. Hispanic Journal of Behavioral Sciences, 38(4), 446-466.

Reed, J., Pritschet, B. L., \& Cutton, D. M. (2013). Grit, conscientiousness, and the transtheoretical model of change for exercise behavior. Journal of Health Psychology, 18(5), 612-619.

Rimfeld, K., Kovas, Y., Dale, P. S., \& Plomin, R. (2016). True grit and genetics: Predicting academic achievement from personality. Journal of Personality and Social Psychology, 111(5), 780-789.

Roberts, B. W., Walton, K. E., \& Bogg, T. (2005). Conscientiousness and health across the life course. Review of General Psychology, 9(2), 156-168.

Robertson-Kraft, C., \& Duckworth, A. L. (2014). True grit: Trait-level perseverance and passion for longterm goals predicts effectiveness and retention among novice teachers. Teachers College Record, $116(3), 1-27$.

Rohrer, J. M. (2018). Thinking clearly about correlations and causation: Graphical causal models for observational data. Advances in Methods and Practices in Psychological Science, 1(1), 27-42.

Ross, C. E., \& Mirowsky, J. (2013). The sense of personal control: Social structural causes and emotional consequences. In C. S. Aneshensel, J. C. Phelan, \& A. Bierman (Eds.), Handbook of the sociology of mental health (pp. 379-402). Dordrecht: Springer Netherlands.

Salles, A., Cohen, G. L., \& Mueller, C. M. (2014). The relationship between grit and resident well-being. The American Journal of Surgery, 207(2), 251-254.

Schmidt, F. T. C., Nagy, G., Fleckenstein, J., Möller, J., \& Retelsdorf, J. (2018). Same same, but different? Relations between facets of conscientiousness and grit. European Journal of Personality, 32(6), $705-720$.

Sharkey, C. M., Bakula, D. M., Gamwell, K. L., Mullins, A. J., Chaney, J. M., \& Mullins, L. L. (2017). The role of grit in college student health care management skills and health-related quality of life. Journal of Pediatric Psychology, 42(9), 952-961. 
Singh, K., \& Jha, S. D. (2008). Positive and negative affect, and grit as predictors of happiness and life satisfaction. Journal of the Indian Academy of Applied Psychology, 34(Special issue), 40-45.

Steel, P., Schmidt, J., \& Shultz, J. (2008). Refining the relationship between personality and subjective wellbeing. Psychological Bulletin, 134(1), 138-161.

Vainio, M. M., \& Daukantaite, D. (2016). Grit and different aspects of well-being: Direct and indirect relationships via sense of coherence and authenticity. Journal of Happiness Studies, 17(5), 2119-2147.

You, S., Hong, S., \& Ho, H.-z. (2011). Longitudinal effects of perceived control on academic achievement. Journal of Educational Research, 104(4), 253-266.

Zack, E. S., Kennedy, J., \& Scott Long, J. (2019). Can nonprobability samples be used for social science research? A cautionary tale. Survey Research Methods, 13(2), 215-227.

Publisher's Note Springer Nature remains neutral with regard to jurisdictional claims in published maps and institutional affiliations. 